\title{
The impact of the macroeconomic stability on the energy- efficiency of the European countries: A bibliometric analysis
}

\author{
Tetyana Pimonenko ${ }^{1 *}$, Yana $U s^{2}$, Liliia Lyulyova ${ }^{3}$, and Natalia Kotenko ${ }^{4}$ \\ ${ }^{1}$ DSc, Associate Professor, Department of Marketing, Sumy State University, Ukraine \\ ${ }^{2} \mathrm{PhD}$ student, Department of Marketing, Sumy State University, Ukraine \\ ${ }^{3} \mathrm{PhD}$ student, Department of Marketing, Sumy State University, Ukraine \\ ${ }^{4} \mathrm{PhD}$, Associate Professor of Finance and Entrepreneurship Department, Sumy State University, Ukraine
}

\begin{abstract}
This paper deals with macroeconomic stability impact on improving the countries' energyefficiency. For that purpose, the authors conducted the bibliometric analysis using the VOSviewer and Scopus tools. The investigation involved 1335 studies focused on economic stability and 1811 studies - on environmental issues. Thus, the obtained results demonstrated the strong links between investigating environmental factors, particularly, energy efficiency, on business performance, economic and macroeconomic stability. Given that, the authors made forecasting energy-efficiency development. In the current research, primary energy consumption was allocated as a basis for forecast the energy-efficiency. The study involves data between 1991 to 2018 from European countries (EU27) taken from the Eurostat database. The methodology of this study was based on ARIMA model. From the results, the authors concluded that the EU energy targets would be gained by 2020. However, the obtained results allow prognosticating increasing the final energy consumption from 2020 to 2029. Based on analysing the EU experience and the forecast findings, the authors allocated the main recommendations to improve the energy-efficiency in Ukraine. The authors noted that current results are considered to be the base for future investigations aimed at the analysis of the macroeconomic stability impact on increasing energy-efficiency level.
\end{abstract}

\section{Introduction}

Nowadays, many countries face new economic challenges. In turn, the developing countries try to transform the macroeconomic policy to increase the resistance to economic shocks. Furthermore, economic growth is considered to be the condition to achieve sustainable development goals which aimed at improving economic activity, social welfare while protecting and saving the environment. Thus, the high rate of economic growth is a result of the effective macroeconomic policy conducted by the government. It worth noting that macroeconomic policy concentrates on the solving the several main tasks as follows: gaining the price stability; reaching the sustainable economic development; providing the total employment and decreasing the poverty level; reducing the balance of payment gap, etc. [1-3]. Developing economic strategies, the governments concentrate on gaining a high rate of economic growth without taking into account the environmental consequences and making worse the ecological situation. However, the macroeconomic policy should provide a positive or, at least, neutral environmental effect. In this case, the twin-win is achieved. However, most of the ecological and economic measures are perforce and compensative concerning the main economic measures. Thus, investigating the linking between macroeconomic policy in the context of sustainable development is a significant task.

Given that, the sustainable development goals accepted to 2030 are to provide the stable growth of people's real income. It worth noting that the sustainable development concept consists of three main components as follows economic, society and ecology. Thus, the measures in the field of sustainable development aimed at increasing economic growth, improving the education system and public health service, providing social protection and employment, fighting against the negative climate changes [4-6].

The EU is considered to be one of the main initiative agents in achieving sustainable development goals. Moreover, the EU investments, credits and partnership provide the economic development of many countries. Notably, the most prominent expanding process of the EU was in 2004, while 10 new countries became the EU members. Despite that it was the most extensive territorial and humanity EU expansion, this was the lowest on the GDP values. Furthermore, the financial crisis in 2008-2009 slowed down the economic growth of new EU members.

Nevertheless, the analysis of the real GDP per capita of the abovementioned countries demonstrates a positive 
tendency for economic growth. Following Figure 1, the highest value of real GDP per capita was in the Czech Republic increased by $40 \%$ in 2019 compared to 2004 (the year of EU integration). In turn, the real GDP growth per capita was in Lithuania increased by $91 \%$ compared to 2004, while in Poland - by $79 \%$, in Latvia by $71 \%$, Slovak Republic - by $70 \%$ and Hungary - by $39 \%$.

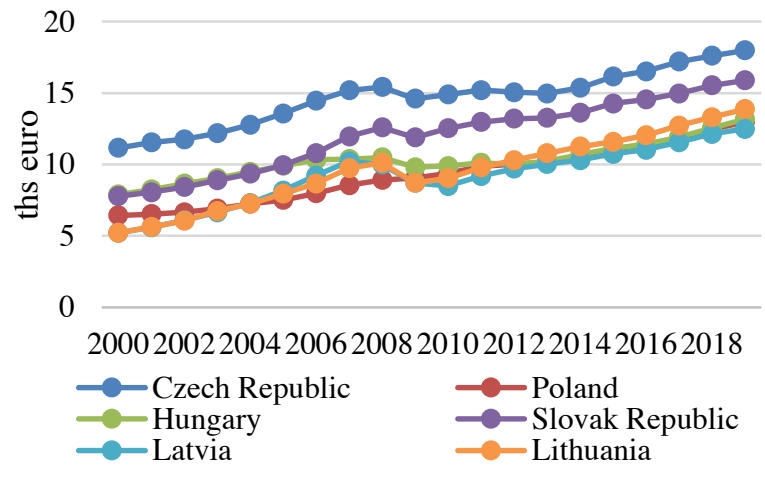

Fig. 1. The dynamics of real GDP per capita in the Chech Republic, Poland, Lithuania, Latvia, the Slovak Republic and Hungary (2000-2019)

*Source: formulated by the authors based on Eurostat data

On the context of economic growth, it is necessary to monitor its impact on the environment. In view of this, the Environment Performance Index (EPI) allowed to estimate the countries' burden on the environment and analyse the rational using natural resources. It worth noting, EPI rates the countries based on their states environment viability, saving the biological variety, reactions to climate changes, human health, the influence of economic development on the environment and government policy in the field of ecology [7-10].

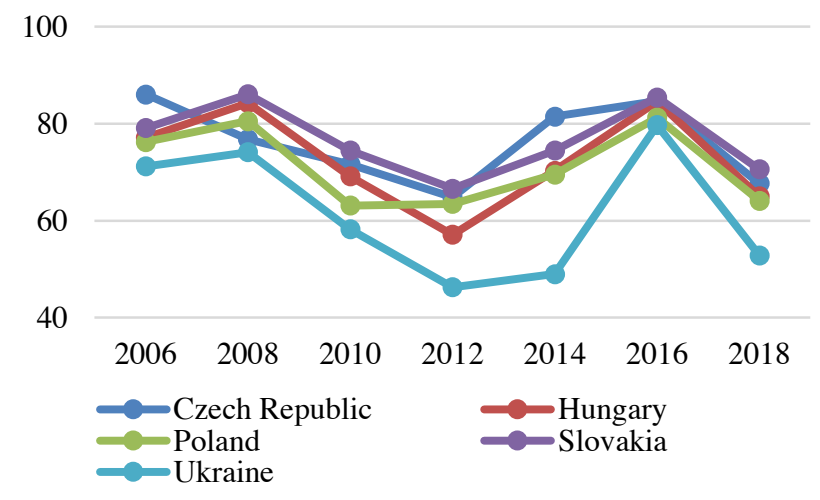

Fig. 2. The Environmental Performance Index dynamic of the Chech Republic, Poland, Lithuania, Latvia, the Slovak Republic and Hungary (2006-2018)

*Source: formulated by the authors

In accordance with Fig. 2, the environmental performance of the EU members (the Chech Republic, Poland, Lithuania, Latvia, the Slovak Republic and Hungary) showed the negative EPI tendency. Notable, that in 2018 the highest decreasing of EPI was in Ukraine (by -26,8), while Ukraine took 109 places among 180 countries. Moreover, Ukraine has the lowest position compared with the EU countries analysed in the current research. In turn, the EPI decreased about by $20 \%$ in Hungary, in Poland and the Chech Republic - by $17 \%$ and Slovakia $-15 \%$.

According to the abovementioned, the economic growth of analysed countries was accompanied by increasing the environmental burden. Thus, investigation of the link between environmental development and economic growth remains pertinent to provide sustainable development.

\section{Literature review}

The strategy bases of economic growth in the light of ecological and social criteria have been developing since the second part of the XX century. In turn, the systematisation of scientific sources [11-15] has indicated a vast research background devoted to investigating issues on macroeconomic stability and environmental factors. In view of this, the scientific interest in investigating environmental determinants as a part of economic stability was analysed using the bibliometric tool VOSviewer. Given that, the analysis of publication activity in the investigated field for the 20002019 period allowed to notice the positive tendency in the publication activity on linking the environmental determinant and economic stability.

In the frame of this study, to analyse the publication activity on influencing the environmental determinants on economic stability, the studies indexed in the Scopus database were considered. In the first stage, we selected the papers based on keywords as follows: "economic stability" and "environmental determinant(-s)". It worth noting that other words related to "environment determinant(-s) as follows "environmental factor(-s), ecological determinant(-s) and "environmental factor(s)" were used in the search. The keywords were examined in the titles, abstracts and keywords. Then, to eliminate the non-referred papers in the field of environmental determinants, we limited to the subject areas as follows: Economics, Econometrics and Finance as well as Business, Management and Accounting. On the third stage, we set the time period from 2000 to 2019 and excluded the inappropriate keywords. Thus, the number of studies focused on the issue of economic stability was 1335 and 1811 studies - on environmental determinants.

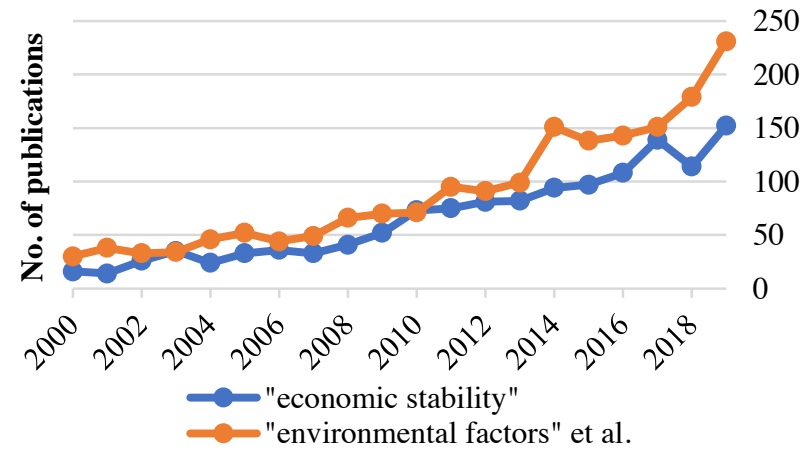

Fig. 3. The dynamic of publication activity on economic stability and environment determinant

*Source: formulated by the authors based on Scopus database 
Following Fig. 3, publication activity on economic stability has a growing trend. Thus, in 2019 the number of papers increased more than 9 times compared to 2000 when 152 works indexed by the Scopus database were published. In turn, Figure 1 shows the growing quantity of articles on environmental determinants. The initial amount of papers was 30 when in 2019 - 231, that is higher more than 7 times compared to 2000 .

The software tool VOSviewer allowed visualising the network map of collaboration between authors from different countries. Generally, 163 countries were involved in investigating environmental determinants as a part of economic stability from 2000 to 2019. In order to highlight the countries with the highest unit weight in reporting on the investigated issue, the selection criteria were a minimum of 5 documents published in a specific country. Thus, following Fig. 4, the reliable communication relationship on the investigated issues between 69 countries expressed in 12 clusters of coauthorship. The first cluster presented the collaboration between the authors from some EU countries and Ukraine; the second - most of all between Australia, the EU countries and the Arab Emirates; the third - between the United Kingdom, the EU countries, Taiwan, Japan, etc. It is worth noting, the bigger size of circles are, the more documents published in co-authorship by the appropriate country. Moreover, the distance between two circles indicated the link strength. The shorter distance is the higher number of papers published in co-authorship between these countries [16].

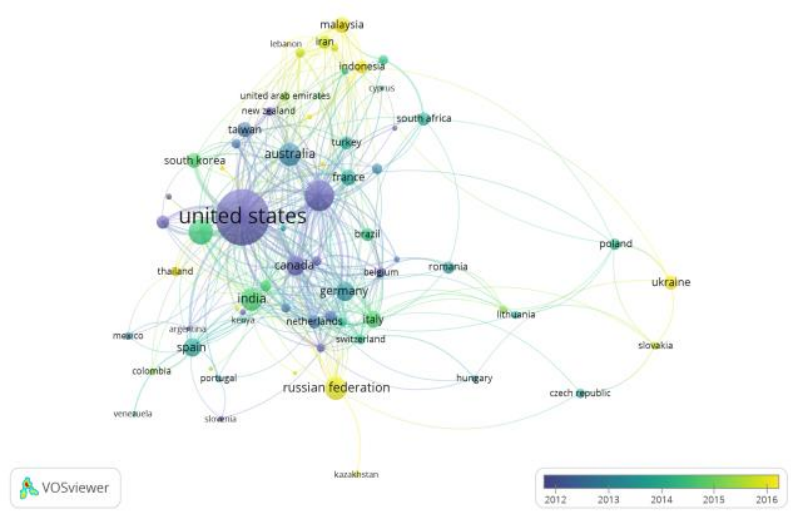

Fig. 4. Bibliometric network map of co-authorship between countries (2000-2019)

*Source: formulated by the authors using VOSviewer software

Under the obtained results, the researchers from the USA had the highest communication activity with researchers from other 51 countries. Moreover, visualised the network map of co-authorship demonstrated that the investigation of the environmental determinant as part of economic stability has begun in the countries as follows the USA, Canada and the United Kingdom since 2012. In turn, this line of research continued in the EU countries, Turkey, Taiwan, India, South Korea, etc. Generally, in Ukraine, the studies in this field have gained in popularity since 2016 .

Fig. 5 demonstrates the thematical direction of analysed massive of publications in the field of economic stability and environmental factors. The terminological map visualises the co-occurrence of keywords in the documents titles, keywords and abstracts. It worth noting that the circle size indicates the frequency of using the particular keyword, the distance between circles - the link strength, while the links show the combination of keywords as inside as outside of the cluster. Thus, there are 10 clusters that combine the keywords on the theme proximity. The biggest red cluster (100 items) concentrated on investigating the environmental factors with competitive advances and business performance. The main research direction of the second green cluster (100 items) investigated the issues of economic stability, environmental performance and energy efficiency. The third blue cluster (52 items) demonstrated the relationship between the topic of macroeconomic stability and competitiveness.

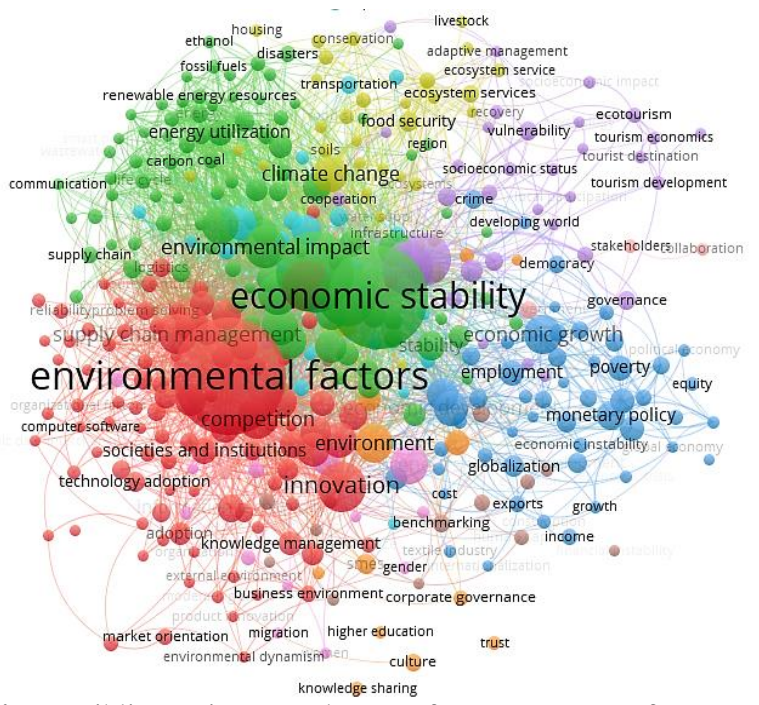

Fig. 5. Bibliometric network map of co-occurrence of keywords (2000-2019)

*Source: formulated by the authors using VOSviewer software

The systematisation of the scientific sources in the field of energy-efficiency indicated a massive set of researches on the investigation of the relationship between energy-efficient issues and increasing economic growth [17-24]. Thus, in the studies [25] the authors considered the influence of society literacy on spreading the energy-efficient technologies in the private sector. In turn, the scientific papers [26-32] were aimed to evaluate the value of green investments and implementing ecoinnovations in decreasing the energy-efficient gaps on the national level. Moreover, in the frame of this article [33] the authors noted that increasing the energyefficient level provided the country competitive growth on the international level. Besides, the researches [3440] were dedicated to analysis the experience of developed countries in implementing the energyefficient projects.

Furthermore, the authors noted the necessity to promote environmentally friendly behaviour among civil society. Thus, the analysis of the scientific literature resources indicates the relevance of future investigation the energy-efficiency as a determinant of macroeconomic stability. Given that, the theme of the 
current research is investigating the impact of energyefficiency on macroeconomic growth.

\section{Methods}

In the frame of this article, the forecast of the energyefficiency was conducted using ARIMA (Autoregressive Integrated Moving Average) model. Notably, $\operatorname{ARIMA}(p, d, q)$ model is the model of autoregression $(A R)$ and integrated moving average $(M A)$, which allows describing the nonstationary series $Y_{t}$, which can be modelled down to stationary by taking d-tuple differences $(I)$. According to the formal description of $\operatorname{ARIMA}(p, d, q)$ model is

$$
\left(\Delta^{d} Y_{t}\right)=c+\sum_{i=1}^{p} a_{i} \Delta^{d} X_{t-1}+\sum_{j=1}^{q} b_{j} \varepsilon_{t-j}+\varepsilon_{t},
$$

where $Y_{t}$ - nonstationary time series;

$\Delta^{d}$ - the difference operator of d-order;

$\varepsilon_{t}-$ the stationary time series;

$c, a_{i}, b_{j}$ - the parameters of the model.

Moreover, the short form of the abovementioned equation of $\operatorname{ARIMA}(p, d, q)$ model is

$$
\varphi(B)(1-B)^{d} X_{t}=\theta(B) \varepsilon_{t},
$$

where $\varphi(\bullet), \theta(\bullet)$ - polynomials of degree $p$ and $q$, $B$ - lag operator $\left(B^{j} X_{t}=X_{t-j}, B^{j} \varepsilon_{t-j}, j=0, \pm 1, \ldots\right)$, $d$ - sequential difference order $\left(\Delta X_{t}=X_{t-1}-X_{t}=\right.$ $\left.(1-B) X_{t}, \Delta^{2} X_{t}=\Delta^{2} X_{t+1}-\Delta X_{t}=(1-B)^{2} X_{t}, \ldots\right)$.

The first approach to develop the $\operatorname{ARIMA}(p, d, q)$ model was proposed by G. Box and G. Jenkins in 1976. According to this methodology, the main steps to develop the model are identification $\rightarrow$ estimation $\rightarrow$ diagnostic checking [41].

It worth noting that the model includes the time series which are stationary after differencing d-times. Herewith, the first step is aimed to determine the degree of difference $(d)$ to make the stationary series using the ACF (PACF) analysis, and the Augmented DickeyFuller unit root test, etc.

Then, the main task in time series analysis is to correctly prescribe the procedure of $\operatorname{ARIMA}(p, d, q)$ model. Therefore, it is necessary to estimate the model parameters $p$ (lag order), $d$ (degree of integration) and $q$ (order of moving average) [42]. In turn, the autoregression model $(A R)$ p-order is described as

$Y_{t}=\varphi_{0}+\varphi_{1} Y_{t-1}+\varphi_{2} Y_{t-2}+\ldots+\varphi_{p} Y_{t-p}+\varepsilon_{t}$

where $Y_{t}-$ the level of time series at the time point $t$ (dependent variable);

$Y_{t-1}, Y_{t-2}, \ldots, Y_{t-p}-$ the levels of time series at the time points $t-1, t-2, \ldots, t-p$ respectively (independent variables);

$\varphi_{0}, \varphi_{1}, \varphi_{2}, \ldots, \varphi_{p}$ - the estimated coefficients;

$\varepsilon_{t}$ - the random walks describing the variable impacts unaccounted for the model (3).
Given this, the coefficient $\varepsilon_{t}$ determines the constant level and related to the expected value $\mu$ formula

$$
\varphi_{0}=\mu\left(1-\varphi_{1}-\varphi_{2}-\ldots-\varphi_{p}\right) .
$$

Using the moving average (MA) model provides the forecasts of functions $Y_{t}$ values based on the linear combination of limited value $q$ remains. In contrast, the autoregression models $(A R)$ gives the forecast of $Y_{t}$ values based on the linear function of approximation of limited value $p$ of the previous $Y_{t}$ values. Herewith, the model with moving average q-order is defined the following equation

$$
Y_{t}=\varepsilon_{t}-\omega_{1} \varepsilon_{t-1}-\omega_{2} \varepsilon_{t-2}-\ldots-\omega_{q} \varepsilon_{t-q},
$$

where $Y_{t}-$ the level of time series at the time point $t$ (dependent variable);

$\varepsilon_{t-1}$ - the values of remains $i$-time periods (independent variables);

$\omega_{1}, \omega_{2}, \ldots, \omega_{q}-$ the estimated coefficients.

The combination of the autoregression model and moving average model is described as the $\operatorname{ARMA}(p, q)$ model. This model allows developing the forecast contingent on as the current and previous values of dependent values, so the current and previous values of random walks.

In the paper [43] general form of $\operatorname{ARMA}(p, q)$ model is

$$
\begin{gathered}
Y_{t}=\varphi_{0}+\varphi_{1} Y_{t-1}+\varphi_{2} Y_{t-2}+\ldots+\varphi_{p} Y_{t-p}+\varepsilon_{t}- \\
\omega_{1} \varepsilon_{t-1}-\omega_{2} \varepsilon_{t-2}-\ldots-\omega_{q} \varepsilon_{t-q} .
\end{gathered}
$$

Thus, the characteristics of the autocorrelation function (ACF) and partial autocorrelation function (PACF) are used to specify the abovementioned parameters. Herewith, to choose the $\operatorname{ARIMA}(p, d, q)$ model it needs to analyse the time series and compare its function structure of the sample and partial autocorrelations with known theoretical structure of $\operatorname{ARIMA}(p, d, q)$ processes. In turn, the examples of simplest $\operatorname{ARIMA}(p, d, q)$ model are the followings:

1) $(1,0,0)$ - average moving;

2) $(1,0,1)-$ cogeneration model of autoregression and moving average;

3) $(1,1,1)$ - the nonstationary process with a linear trend.

The object of this research is the EU countries. On the base of this criterion, the primary energy consumption of 27 EU countries from 1991 to 2018 were analysed to make its forecast to 2030 .

\section{Results and Discussion}

The analysis of statistical data allowed noting that Ukraine had a negative tendency on primary energy consumption. Thus, in 2018 the final energy consumption decreased by more than $64 \%$ compared to 1991. However, this level of primary energy 
consumption is continuously higher than the EU average level (Fig.6).

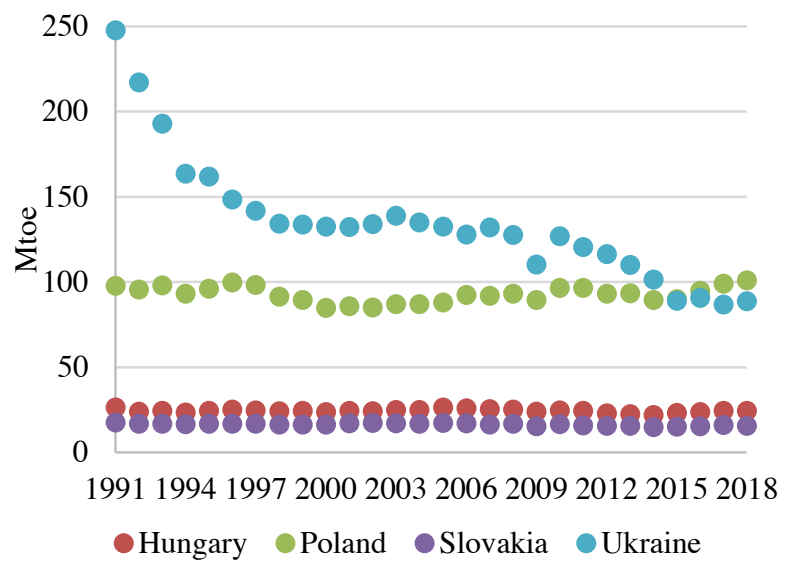

Fig. 6. The dynamics of primary energy consumption in the Czech Republic, Poland, Lithuania, Latvia, the Slovak Republic and Hungary (1991-2018)

*Source: formulated by the authors based on Eurostat data

Herewith, EU is considered to be the leader in fighting against climate change. In turn, to intensify forces and improve the level of energy-efficiency, the European Parliament and the Council accepted the Directive 2012/27/EU. It worth noting that increasing energy-efficiency allows reducing environmental emissions, improving industry safety, providing better living conditions, extending the equipment and building life cycles, implementing innovations, etc. Under the abovementioned Directive, the level of EU energy consumption has to be decreased by $20 \%$ to 2020 (no more than 1483 Mtoe of primary energy consumption and 1086 Mtoe of final energy consumption) [44]. Furthermore, the 2030 Framework for Climate and Energy set the targets to decrease the energy consumption by $32,5 \%$ to 2030 (no more than 1273 Mtoe of primary energy consumption and 956 Mtoe of final energy consumption).

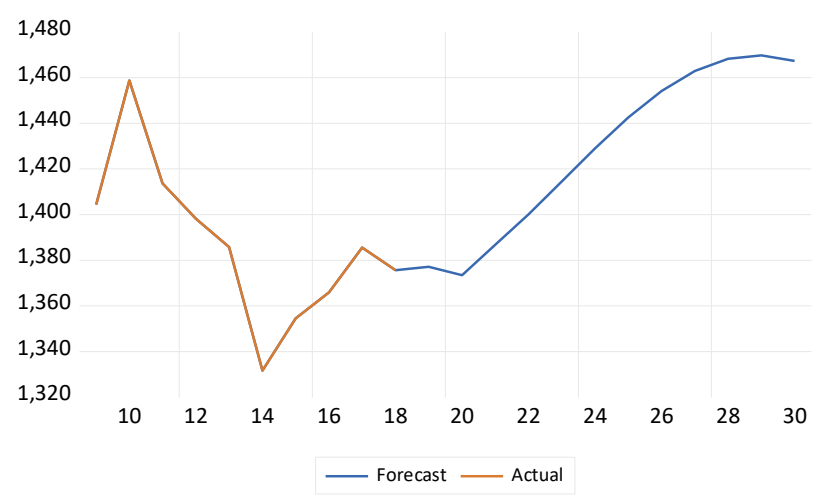

Fig. 7. The forecast of final energy consumption (Mtoe) by the EU27 (1991-2030)

*Source: formulated by the authors using the Eviews software

Figure 7 demonstrates the forecast on the energyefficiency conducted using ARIMA model. The determinate sample is total primary energy consumption (Mtoe) by EU27 from 1991 to 2018. The Augmented
Dickey-Fuller unit root test was used to check the stationarity of time series. Thus, the conducted forecast showed that to 2020 the primary energy consumption in EU27 would decrease. Herewith, providing the primary energy consumption be 1373 Mtoe in 2020, the EU energy target would be gained (Fig.7). However, the obtained results allow prognosticating increasing the final energy consumption from 2020 to 2029. Under the abovementioned, in future investigations, it is necessary to analyse the macroeconomic impact on the energyefficiency level.

\section{Conclusions}

The current stage of gaining world economic development indicates the high significance of macroeconomic stability. In turn, the macroeconomic stability depends on increasing the energy-efficiency, decreasing the environment emissions, improving energy productivity, etc. Thus, in the frame of this paper, the link between energy-efficiency and macroeconomic stability was analysed.

The conducted bibliometric analysis indicated the growing publication activity on the investigated theme. The obtained results showed 10 clusters which displayed theme proximities of analysed publications. The main research direction concentrated on investigating the environmental factors with competitive advances and business performance; the issues of economic stability, environmental performance and energy efficiency; the relationship between the topic of macroeconomic stability and competitiveness.

Using the ARIMA model with minimal parameters, the forecast for EU primary energy consumption was conducted. The obtained results indicated that the EU energy goals would be gained in 2020. The abovementioned allowed assuming that the EU energy policy was effective. Thus, the Ukraine energy strategy has to be concentrated on reducing energy consumption by increasing the energy-efficiency level, implementing renewable energy sources, attracting green investments, etc. However, to make the accurate forecast for 2030 , the future investigations would be aimed at the analysing the impact of macroeconomic stability on energy-efficiency.

\section{Funding}

This research was funded by the grant from the Ministry of Education and Science of Ukraine (№0117U003932; 0118U003569).

\section{References}

1. Bonamigo, D. Mendes, Business Ethics and Leadership, 3(4), 66-73 (2019)

2. T. Vasylyeva, S. Pryymenko, Actual Problems in Economics, 160, 252 (2014)

3. A. Vysochyna, I. Samusevych, V. Tykhenko, Actual Problems in Economics, (171), 263 (2015) 
4. Bonamigo, D. Mendes, Business Ethics and Leadership, 3(4), 66-73 (2019)

5. G. Mentel, T. Vasilyeva, Y. Samusevych, S. Pryymenko, International Journal of Environmental Technology and Management, 21(5-6), 354-372 (2018)

6. V. Pavlyk, Financial Markets, Institutions and Risks, 4(1), 117-123 (2020).

7. H. Dkhili, L. Dhiab, Marketing and Management of Innovations, 4, 252-268 (2019)

8. T. Pimonenko, L. Lyulyova, Y. Us, Environmental economics, 8, 4, 53-61 (2017)

9. I. Sotnyk, O. Volk, Y. Chortok, Actual Problems of Economics. 147(9), 229-23 (2013)

10. Y. Bilan, S. Lyeonov, O. Lyulyov, T. Pimonenko, Polish Journal of Management Studies, 19(2), pp. 61-74 (2019)

11. V. Pavlyk, SocioEconomic Challenges, 4(1), 122128 (2020)

12. Y. Yevdokimov, O. Chygryn, T. Pimonenko, O. Lyulyov, Innovative Marketing, 14(2), 7-15 (2018)

13. J. Alam, B. Rashid, SocioEconomic Challenges, 3(3), 98-107 (2019)

14. K. Akpoviroro, A. Olalekan, S. Alhaji, Business Ethics and Leadership, 2(4), 99-107 (2018)

15. L. Sokolenko, I. Tiutiunyk, D. Leus, International Journal of Ecology and Development, 32(3), 27-35 (2017)

16. Ya. Us, S. Bilan, T. Pimonenko, R. Seliga, G. Ostasz, Green brand for sustainable business: bibliometric analysis, in Proceedings of the 35th IBIMA Conference: 1-2 April 2020, Seville, Spain (2020)

17. S. Leonov, H. Yarovenko, A. Boiko, T. Dotsenko, Information system for monitoring banking transactions related to money laundering, TCEUR Workshop Proceedings 2422, 297-307 (2019)

18. O. Lyulyov, O. Chygryn, T. Pimonenko, Marketing and Management of Innovations, 3, 142-152, (2018)

19. S. Formankova, O. Trenz, O. Faldik, J. Kolomaznik, P. Vanek, Marketing and Management of Innovations, 2, 94-102 (2018)

20. S. Vegera,A. Malei, O. Romanova, V. Sushko, Marketing and Management of Innovations, 4, 244262 (2018)

21. T. Goncharenko, Business Ethics and Leadership, 4(1), 113-125 (2020)

22. T. Vasylyeva, S. Leonov, O. Lunyakov, Actual Problems in Economics, (8), 278-283, (2014)

23. Ab. Moskovicz, Financial Markets, Institutions and Risks, 2(1), 75-78 (2018)

24. Grenčíková, Y. Bilan, Y. Samusevych, A. Vysochyna, Drivers and inhibitors of entrepreneurship development in central and eastern European countries, in Proceedings of the 33rd International Business Information
Management Association Conference, IBIMA, pp. 2536-2547 (2019)

25. E. Ozsoy, Marketing and Management of Innovations, 1, 11-20 (2019)

26. V. Panchenko, Yu. Harust, Ya. Us, O. Korobets, V. Pavlyk, MMI, 1, 256-264 (2020)

27. I. Sotnyk, Actual Problems of Economics, 134(8), 62-67, (2012)

28. Y. Bilan, T. Vasylieva, S. Lyeonov, I. Tiutiunyk, Entrepreneurial Business and Economics Review, 7(2), 27-43 (2019)

29. M. AUgbaka, A. Awujola, T. Shcherbyna, SocioEconomic Challenges, 3(4), 5-12 (2019)

30. H. Dave, The X-ray report of "Economic growth". Financial Markets, Institutions and Risks, 3(4), 8993 (2019)

31. Y. Bilan, O. Kuzmenko, A. Boiko, Research on the impact of industry 4.0 on entrepreneurship in various countries worldwide, in Proceedings of the 33rd International Business Information Management Association Conference, IBIMA, 2373-2384 (2019)

32. K. Kasztelnik, Financial Markets, Institutions and Risks, 4(1), 60-75 (2020)

33. O. Chygryn, T. Pimonenko, O. Luylyov, A. Goncharova, Journal of Environmental Management and Tourism, 9 (7), pp. 1443-145 (2018)

34. M. Taqi, N. Gurkaynak, M. Gencer, Marketing and Management of Innovations, 2, 185-197 (2019).

35. Y. Bilan, S. Lyeonov, T. Vasylieva, Y. Samusevych, Online Journal Modelling the New Europe, (27), pp. 34-66 (2018)

36. Yu. Harust, V. Melnyk, Marketing and Management of Innovations, 4, 373-382 (2019)

37. O. Kozmenko, O. Kuzmenko, Investment Management and Financial Innovations, 8(2), 8-16 (2011)

38. S. Lyeonov, T. Pimonenko, Y. Bilan, D. Streimikiene, G. Mentel, International Journal of Business and Society. 20(2), pp. 433-450 (2019)

39. J. Cebula, O. Chygryn, S. Chayen, T. Pimonenko, International Journal of Environmental Technology and Management, 21(5-6), pp. 421-438 (2018)

40. Y. Bilan, T. Vasilyeva, O. Lyulyov, T. Pimonenko, International Journal of Business and Society, 20(2), 433-450 (2019)

41. O. Kuzmenko, S. Kyrkach, Mathematical Formalization of the Stages of Financial Planning in Banks (2014)

42. A. Tregub, N. Tregub, Forestry Bulletin, 5 (2011)

43. N. Shamaeva, Buletin of economic science of Ukraine, 1 (2014)

44. O. Tverdokhlib, Marketing and Management of Innovations, 1, 362-370 (2018) 